\title{
O Grupo de Teatro Mambembe e o Circo-Teatro
}

\author{
Rubens de Souza Brito
}

Grupo de Teatro Mambembe, fundado no início de 1976 por Carlos Alberto Soffredini e mais dezesseis artistas, estreara, em novembro desse mesmo ano, com $A$ Vida do Grande D. Quixote de La Mancha e do Gordo Sancho Pança, adaptação realizada pelo elenco da peça homônima que Antônio José plasmou da obra prima de Cervantes. O espetáculo, patrocinado pelo SESC, foi criado especialmente para ser representado nas praças públicas da capital e do interior do Estado de São Paulo (na época, ainda não era usual o emprego do termo "teatro de rua").

Entre a reunião do elenco e a estréia, o grupo realizou uma intensa pesquisa nos circosteatros, os quais se apresentavam na periferia da capital, em especial no Circo-Teatro Bandeirantes, o maior e o mais bem equipado de todos. É no circo-teatro que o Mambembe encontra os elementos essenciais do espetáculo popular.

Quem assiste às peças circenses e ao $D$. Quixote identifica de imediato a utilização do mesmo tipo de espaço cênico: palco elisabetano, telōes pintados ao fundo e o público envolvendo a cena (na representação mambembeira, o palco, exibindo uma dimensão de $14 \mathrm{~m}$ x $12 \mathrm{~m}$, posiciona-se a uma altura de $1,80 \mathrm{~m}$ para não prejudicar a visibilidade da platéia, composta, em média, por 2.000 pessoas).

Irineu Chamiso Júnior, Eurico Sampaio e Júlio Moraes, além de cenógrafos, figurinistas e atores do grupo, incluem na programação visual do espetáculo quixotesco (que se concretiza através de telóes, figurinos, adereços, objetos, maquiagem e bonecos) toda a gama de sugestôes emanadas pela estética espetacular do circo-teatro.

O mesmo tipo de procedimento é adotado pelos músicos-atores Tato Fischer, Mário César Camargo e José Roardo (substituído por Wanderley Martins) em relação à música e às intervenções musicais. Aqui, a música popular brasileira e sua utilização na cena circense são a fonte do estudo. Apoiando-se nesses elementos, nas chanchadas da Atlântida e nos musicais hollywoodianos, Soffredini e a atriz-coreógrafa Noemi Gerbelli elaboram uma sofisticada e envolvente coreografia.

Preocupado com o caráter essencial da interpretação no fenômeno teatral, o Mambembe dirige seu olhar para o ator circense, redobrando os cuidados com o estudo de seu desem-

Rubens de Souza Brito é professor do Departamento de Artes Cênicas da Unicamp. Este ensaio baseiase, parcialmente, na tese de livre-docência: Teatro de Rua: princípios, elementos e procedimentos - a contribuição do Grupo de Teatro Mambembe (SP). Campinas: Unicamp, 2004. 
penho. Esse é, para os integrantes da companhia, o grande mistério a ser desvendado.

Os "professores" do Mambembe são perfeitos na condução da encenação e no domínio do público. Mergulhando por inteiro nos melodramas, nas "altas comédias", nos esquetes, nas entradas e reprises, os atores do circo-teatro ensinam o passo-a-passo da criação e representação das personagens. A lição primeira é a de causar espanto: o descompromisso do artista em relação a qualquer tipo de medo. $\mathrm{O}$ medo de errar, o de não agradar, o de ser ridículo, o de ser "pichado" pela crítica. Liga-se a essa primeira, a segunda lição: a liberdade de se apropriar de tudo aquilo que ele quer a fim de criar sua personagem. Ele se dá o poder de incorporar a ela, a música que está no primeiro lugar da parada, o figurino da moda ou o sotaque de algum personagem conhecido da televisão. É no tablado do circo-teatro que se entende claramente o que é liberdade de criação. Ambas as lições preparam a terceira, esta, ministrada pelo cômico da companhia (no caso do Circo-Teatro Bandeirantes, o ator Marco Antônio Martini, o "Chico Biruta"): como fazer o público rir! Como construir uma piada! Como "segurar" uma platéia! Lições que o Mambembe pôde aprender "ao vivo", sob a lona mágica (e, muitas vezes, furada) dos circos-teatros. Infelizmente, são poucos, atualmente, os que perambulam pelo país. O conjunto de aulas cumpre uma função essencial, talvez a principal da arte cênica, a de divertir! (Brecht também compartilha dessa opinião acerca do teatro).

Ao menos, assim foram compreendidas as aulas pelos atores e atrizes do Mambembe: Flávio Dias, Rubens Brito, Ednaldo Freire, Calixto de Inhamuns, Douglas Salgado, Sérgio Rossetti, Artelino Macedo, Suzana Lakatos, Eunice Mendes e Simone Miranda (substituída por Rosi Campos).
O elenco descobre, ainda, que havia um "suporte", um tipo de "estrutura" que formatava, a partir da interpretação, o próprio espetáculo.

Tratava-se daquilo que o grupo viria a denominar de triangulação.

Soffredini explica este conceito: "O ator [do circo-teatro] se entrega sim, ele se envolve sim, mas em nenhum momento ele se esquece que está num palco, nem por um segundo ele ignora o público. Pelo contrário: na maior parte das vezes ele "contracena" com o público, estabelecendo o que nós chamamos de "triângulo". Assim: dois atores em cena; UM deve fazer uma pergunta para o OUTRO; ${ }^{1}$ UM faz a pergunta para o público e não diretamente para o OUTRO (nada de relação olho-no-olho, portanto); e o OUTRO responde também através do público. Parece uma coisa simples, mas essa forma de contracenar sempre "através" do público póe este último sempre no centro da representação. Outra forma de estabelecer o triângulo: as açôes e reações de um ator (personagem) estão sempre abertas para o público (não há psicologismos e por isso não há jogos escondidos). Se um ator, por exemplo, reage ao que um outro ator está dizendo ele "diz" (mesmo sem palavras) a sua reação diretamente para o público. Dessa forma, pode-se também, por exemplo, valorizar muito cada nuança da intenção de um ator que fala, através da reação que ele causa no seu interlocutor. Mas vamos falar mais sobre o processo do Triângulo que é, observamos, a base de qualquer tipo de apresentação popular. $\mathrm{O}$ público é o vértice de maior peso no triângulo. É o CÚMPLICE na representação. É o CENTRO dela. É para ele que se CONTA a história, portanto ele é o dono dessa história. Muitas vezes ele conhece dados dela que ou um ou os outros dois vértices do triângulo (os atores) desconhecem. Ele conhece o caráter e a intenção de cada personagem, uma

1 Todos os grifos, em caixa alta, são de Soffredini. 
vez que cada ator, ao entrar em cena, deve Ter como meta REVELAR o seu personagem, a intenção dele e, é claro, a sua ação dentro da ação (história). A partir dessa CUMPLICIDADE com o público, dessa CENTRALIZAÇÃO nele, dessa DOAÇÃO a ele da ação (história, representação) é que se estabelece a base do jogo teatral. Os gregos já sabiam disso. $\mathrm{E}$ as velhas peças românticas abriam margem para esse jogo através do A PARTE, que, em última análise, é a forma tosca a partir da qual, elaborando, nós chegamos ao processo do TRIÂNGULO. (...) Trata-se de espicaçar o jogo teatral. Trata-se de assumir a teatralidade do Teatro. Trata-se de derrubar a quarta parede com picaretas...(...) Os dois outros vértices do triângulo estão no palco. São os atores. Certa vez fomos assistir a uma família chinesa num Circo. Eram equilibristas. A família era formada pelo pai, a mãe e nove filhos nas idades mais variadas. $\mathrm{O}$ espetáculo era lindíssimo. O pai e os nove filhos eram realmente muito bons artistas. E a mãe? Bem, a mãe não sabia fazer nada. Ela ajudava os artistas na troca e arrumação dos aparelhos e se colocava num ponto estratégico no decorrer dos números. E, no entanto, ela era a figura central do espetáculo. A platéia, ao mesmo tempo em que via os artistas, não conseguia se desligar dela. Por que? Sem dizer uma palavra, apenas sublinhando com expressões, ela "dimensionava" os números a medida em que eles iam se realizando: expectativa enquanto os artistas se preparavam; apreensão quando o número se aproximava do seu ponto mais difícil; desapontamento quando o número falhava (propositalmente, é claro) perto de se realizar; alívio quando o "difícil" do número passava; entusiasmo quando o artista pedia aplauso...Evidentemente a mãe estava colocada ali para valorizar a performance do artista, conferindo ao seu feito uma dificuldade que, de resto, muitas vezes ele não tinha. Colocada no palco como um espectador do número (identidade com o público), ela, numa relação direta com o espectador, agia como se espelhasse a reação deste, quando na verdade estava mais é definindo essa reação. Ela fazia o que nós passa- mos a chamar de PONTE. Aqui seria interessante observar que não se deve confundir a PONTE com o ESCADA (apenas para lembrar: "escada" é o interlocutor de um palhaço, um cômico ou um personagem, que é colocado em cena apenas como pretexto para que o palhaço faça suas palhaçadas, o cômico diga suas piadas ou o personagem se manifeste), embora todo bom escada deva estabelecer a PONTE. Muitas vezes a PONTE pode ser estabelecida pelo elemento central da cena (o palhaço, o cômico ou o personagem). Tentando elucidar: se um personagem diz um absurdo, o outro personagem reage a esse absurdo na PONTE, o que dimensiona o absurdo dito. Se o personagem que diz o absurdo tem consciência dele, ele próprio pode comentar isso (não necessariamente com palavras) na PONTE, antes ou depois ou ao mesmo tempo em que fala. E se não tem certeza do que está dizendo, também na PONTE pode revelar essa dúvida. Enfim, o painel é riquíssimo no que diz respeito à PONTE e a sua dosagem ou lugar vai servir a um diferente "efeito pretendido." (...) Ah - vão dizer, dando uma olhada nas bases acima expostas -, algumas coisas cheiram a Brecht. E cheiram mesmo. Acho que é porque Brecht estabeleceu as bases de seu método indo pesquisar as formas populares de representação. Talvez esteja aí o ponto de contato: no popular. É claro que o popular brasileiro é diferente do popular alemão... mas deve haver pontos de contato. Deve, digo, porque não conheço o popular alemão. Estou tentando conhecer o brasileiro" (Soffredini, 1980).

Vale destacar alguns aspectos do conceito examinado pelo autor de $\mathrm{Na}$ Carreira do Divino.

A triangulação posiciona-se como uma técnica de interpretação, e, enquanto instrumental interpretativo, atribui determinadas características ao espetáculo teatral. Talvez, a principal, seja a de incluir o espectador no jogo cênico: o espetáculo não é feito PARA a platéia e sim, COM a platéia. Daí Soffredini fazer a referência "o público é o vértice de maior peso no triângulo”.

Ao incluir os espectadores no jogo cênico, as personagens transformam-se em "cúmpli- 
ces" destes mesmos espectadores; a cumplicidade, por sua vez, dá-se através da ponte que cada um dos atores estabelece com a platéia.

No entanto, é preciso salientar que existem diferenças entre a ponte efetivada pelo cômico do espetáculo e as das demais personagens. O primeiro é "o representante da platéia no jogo cênico que se realiza no palco"; "o ponto de vista" da peça é sempre dele. Ele é o "apresentador" das figuras e do espetáculo; no D. Quixote mambembeiro, Sancho Pança exercia essa função.

Estabelecida a cumplicidade, através da ponte, criam-se as condições para a instalação da plenitude do jogo cênico: já não existe mais distinção entre palco-platéia. $\mathrm{O}$ que existe é o jogo cênico “jogado" por palco e platéia.

É importante notar que, para estabelecer a ponte, $\mathrm{o}$ ator, obrigatoriamente, "distancia-se" da situação dramática da cena para, na seqüência, levá-la ao público; há, portanto, um "deslocamento" da situação dramática, deslocamento esse, realizado pelo intérprete. Conseqüentemente, a triangulação propõe ao ator um tipo de interpretação no qual não basta que ele "seja" a personagem, mas que ele "seja" a personagem e a revele para o público. Essa é a razão pela qual Soffredini remete esse fenômeno ao teatro brechtiano.

Segundo o autor de $O$ Pássaro do Poente, "os gregos já sabiam..." que a cumplicidade, a centralização do espetáculo no público e a doação à platéia da representação são as bases do jogo teatral. É notório, entretanto, que o jogo cênico estruturado na triangulação se dimensiona e se consagra na commedia dell'arte.

A triangulação nas peças circenses é explícita e executada com muita naturalidade. $\mathrm{O}$ espetáculo se desenvolve de forma a incluir a platéia no jogo cênico, especialmente nas comédias; nos dramas se observa o mesmo fenômeno, embora a técnica triangular se atenue em benefício da objetivação da "dramaticidade" do enredo.

Alguns atores se destacam pelo domínio e precisão no emprego da triangulação. No Cir-
co-Teatro Bandeirantes, destacava-se "Chico Biruta", um "descendente legítimo dos commicci dell'arte". Com ele e seus parceiros, o elenco do Mambembe aprendeu e sistematizou o jogo cênico desenvolvido através da triangulação, técnica utilizada em $D$. Quixote (1976) e em seus dois espetáculos seguintes, $O$ Diletante (1977), de Martins Pena, e Farsa de Inês Pereira (1977), de Gil Vicente.

Uma parcela da classe teatral paulistana que não assistira ao D. Quixote na Praça da República compareceu ao Teatro Anchieta quando a peça foi ali apresentada, cumprindo uma curta temporada, e se surpreendeu com a técnica de interpretação apresentada. O elenco recebeu, então, um convite para dar uma aula prática sobre essa técnica. A demonstração se realizou no Teatro de Arena de São Paulo com a presença de inúmeros artistas. Esse evento foi muito significativo para o Mambembe - uma espécie de reconhecimento - pois o elenco estava ali reunido com parte da classe artística de São Paulo, num dos espaços sagrados do Teatro Brasileiro.

Para chegar à sistematização, o Mambembe elaborou um treinamento objetivando o exercício da triangulação de forma a incluir o público no jogo cênico através de um trabalho gestual preciso. $\mathrm{O}$ grupo entendia que a exatidão das açõos físicas era uma condição absolutamente essencial da técnica triangular empregada no espaço cênico da praça pública; a nitidez das açôes permitia o entendimento da personagem e da cena no ambiente dispersivo da praça. Soffredini manifestava preocupação com a precisão nas ações dos atores: "Nós fomos nos exercitando num trabalho de interpretação que busca o limpo, o direto, o contundente. Nisso muito nos ajudou uma passada pelo teatro japonês, principalmente o Nô, onde um pequeno gesto de ombro tem enorme dimensão e é prenhe de clareza e significado exatamente porque é "dado" no meio de total imobilidade" (Soffredini, 1980). A maior dificuldade do treinamento se situava na compreensão e no domínio da reação como elemento integrante e essencial: o momento de sua reali- 
zação é o momento no qual se estabelece o diálogo franco com a platéia. Após o emprego da triangulação em três espetáculos, os atores do Mambembe conseguiram o domínio dessa técnica. A disposição gráfica abaixo sintetiza a triangulação em processo:

\section{A triangulação}

Os oito movimentos de uma ação completa: ${ }^{2}$

\begin{tabular}{|c|c|c|c|}
\hline $\mathrm{A}=$ Ator $\mathrm{A}$ & & & $\mathrm{B}=$ Ator $\mathrm{B}$ \\
\hline $1^{\circ}$ Movimento) & (;) $\rightarrow$ & () B & Ação (de A) \\
\hline 2o Movimento) & ():A & $\rightarrow \odot \mathrm{B}$ & Recepção (de B) \\
\hline $3^{\circ}$ Movimento) & (-)A & $\begin{array}{c}\odot \mathrm{B} \\
\downarrow\end{array}$ & $\begin{array}{l}\text { Construção } \\
\text { da Reação }\end{array}$ \\
\hline $4^{\circ}$ Movimento) & ;)A & $\begin{array}{c}\odot \mathrm{B} \\
\uparrow\end{array}$ & $\begin{array}{l}\text { Incorporação } \\
\text { da Reação } \\
\text { (preparação da ação) }\end{array}$ \\
\hline $5^{\circ}$ Movimento) & ;)A & $\leftarrow \odot \mathrm{B}$ & Ação (de B) \\
\hline $6^{\circ}$ Movimento) & (;) $\mathrm{A} \leftarrow$ & (:) B & Recepção (de A) \\
\hline 7o Movimento) & $\begin{array}{c}\odot \mathrm{A} \\
\downarrow\end{array}$ & () B & $\begin{array}{l}\text { Construçãao } \\
\text { da Reação }\end{array}$ \\
\hline $8^{\circ}$ Movimento) & $\begin{array}{c}\odot \mathrm{A} \\
\uparrow\end{array}$ & (:) B & $\begin{array}{l}\text { Incorporação } \\
\text { da Reação } \\
\text { (preparação da ação) }\end{array}$ \\
\hline
\end{tabular}

“9o Movimento" = 10 Movimento

O sistema pode ser interpretado da seguinte forma:

A triangulação considera os oito movimentos como constituintes de uma única ação dramática. Essa única ação corresponde, por sua vez, a uma unidade mínima do jogo cênico em triangulação.

$\mathrm{O}$ ator A dirige uma ação para o Ator B. Neste primeiro movimento, a noção de direção fundamenta a triangulação. Nesse sentido, o estudo de Rudolf Laban sobre o movimento pode ser útil para a elucidação dos atributos em jogo na triangulação. A ação produzida pelo Ator A significa, antes de tudo, que ele é quem está com a ação: na triangulação é essencial que o público saiba com quem está a ação.

$\mathrm{O}$ ator $\mathrm{B}$, no segundo movimento, recebe a ação que lhe foi dirigida pelo Ator A. Para receber a ação, o Ator $\mathrm{B}$ deve estar focado na ação do Ator A. Com isso, o Ator B está direcionando o olhar do público para o Ator A. Ao finalizar sua ação, o Ator A também deve focar sua atenção no Ator B; igualmente, está dirigindo a atenção da platéia para o Ator B. Dessa situação, surge um princípio vital na triangulação: quem não está com a ação foca quem está com a ação. Esse procedimento é que direciona o olhar do público. Essa forma de proceder também é válida para o caso de a cena se desenrolar com mais de dois atores: em cada uma dessas cenas, os espectadores devem saber com quem está a ação. Ao terminar de receber a ação, o Ator B "corta" a relação olho-no-olho em andamento com a personagem A, virando-se em direção ao público: a partir desse instante, ele está pronto para reagir à ação.

O Ator B, no terceiro movimento, estando de plena posse da ação recebida do Ator A, reage em função dessa ação, e direciona sua reação para o público. Isto corresponde à reação (e não a uma ação), que deve ser construída através de um único gesto corporal. Esse gesto corresponde a uma máscara, que tem a função primária de revelar, com extremo rigor, e de uma só vez, a verdade da personagem interpretada pelo Ator B. Essa máscara é, portanto, exata, clara e precisa. Existe um intervalo de tempo entre o início e o fim da construção da máscara. É preciso ficar muito claro para a platéia quando se inicia a construção da máscara (início da reação) e quando esta máscara se completa (final da reação). Para tanto, o ator pode recorrer ao conceito de acento proposto por Laban. A magia desse movimento reside na re-

2 Sistematização elaborada pelo autor deste ensaio. 
velação ao público de como o ator constrói a máscara. A máscara em construção é a magia que a triangulação proporciona ao público: é nesse momento que o ator revela a verdade de sua personagem, mostra como ele, ator, constrói a reação da personagem e, finalmente, mantendo a atenção dos espectadores, inicia o processo de inclusão da platéia no jogo cênico.

Estabelecida a máscara, tem início o quarto movimento: a personagem (Ator B), agora, deve incluir em seu universo a reação que ela teve em relação à ação proposta pela personagem interpretada pelo Ator A. É como se a personagem, para incluir a sua reação "em seu universo", perguntasse: "Em vista do quê recebi e do como reagi, o que é que eu faço agora? Esse é o mesmo tipo de pergunta que a platéia está se fazendo naquele instante: "O quê essa personagem vai fazer agora?”. Enquanto a personagem "pensa no que fazer" estabelece-se um intervalo de tempo que corresponde à manutenção da intenção da máscara final, a qual permanece ali, posta; essa espécie de "congelamento" da máscara é fundamental para o jogo cênico em triangulação, pois é o momento em que a personagem induz a platéia a também procurar respostas: é o passo decisivo para a instituição da cumplicidade plena entre o palco e a platéia. Quando sobrevém a idéia do quê a personagem deve fazer, imediatamente o Ator $\mathrm{B}$ inicia o processo de desconstrução da máscara: o público identifica rapidamente esse passo. Desconstruída a máscara, ou seja, desconstruída a reação, o Ator B começa a construir uma nova máscara: a da intenção da ação que direcionará para o Ator A. Ainda não se trata da ação propriamente dita, mas sim da construção da intenção da ação: a platéia pode não saber exatamente o quê a personagem (Ator B) vai fazer. Mas, com certeza, quando o Ator $B$, no próximo movimento $\left(5^{\circ}\right)$, direcionar esta ação para o Ator $\mathrm{A}$, o público já conhecerá essa máscara por inteiro, isto é, a sua intenção da ação e, portanto, ele, o público, vai querer saber como a personagem (Ator $\mathrm{A}$ ) receberá e como reagirá a essa ação que lhe foi dirigida pelo Ator B. Por isso, quando a máscara da intenção estiver composta, o Ator $\mathrm{B}$, mantendo a intenção da ação que ele criou, desfaz a relação direta que estava tendo com a platéia e se vira para o Ator A: somente aí é que o Ator $\mathrm{B}$ direciona a ação para o Ator A; com esse comportamento, o Ator B direciona o olhar do público para o Ator A.

Esse procedimento corresponde ao $5^{\circ}$ Movimento. É preciso notar que, num espetáculo circense ou mesmo no D. Quixote do Mambembe, o movimento de construção da máscara da intenção era o momento no qual o ator podia, inclusive, incorporar sugestôes dadas pelo público; dessa forma, quando o ator acionar em direção ao outro ator, o estímulo dado pela platéia estará contido na sua ação. Em síntese, o ator inicia o $4^{\circ}$ Movimento partindo da máscara momentaneamente "congelada" ao final do $3^{\circ}$ Movimento para, a partir da "idéia" da ação que deverá construir, começar a desconstrução dessa máscara; uma vez "desconstruída" a máscara da reação, o ator principia a elaborar a máscara da intenção, incluindo, eventualmente, as sugestôes dadas pelo público. Uma vez pronta a máscara da intenção, o ator pode liberar a relação olho-no-olho que até então manteve com os espectadores e aí, sim, direcionar essa ação para o outro ator. Deve-se a Carlos Alberto Soffredini a elaboração desse movimento da construção da máscara da reação, da subseqüente desconstrução dessa máscara e a proposição de uma nova máscara, a da intenção, a qual será utilizada na ação de um ator/personagem para o outro ator/personagem. Esse movimento é, de fato, mágico. Todo esse processo é revelado para o público, que se surpreende com a magia da elaboração teatral, ao mesmo tempo em que se deixa envolver pela teatralidade impressa por esse tipo de jogo cênico. $\mathrm{O}$ ator não faz nada "escondido" do público; ao contrário, o ator revela sua criação, incorpora a reação do público em seu jogo e direciona a platéia para o jogo do outro ator; é dessa forma que a triangulação incorpora o público no jogo cênico. 
O $5^{\circ}$ Movimento se processa da mesma forma que o $1^{\circ}$, sendo a única diferença o direcionamento da ação, o qual, no caso, é realizado pelo Ator B.

O $6^{\circ}$ Movimento assemelha-se ao $2^{\circ}$; no entanto, quem processa a reação é o Ator A.

O $7^{\circ}$ e o $8^{\circ}$ Movimentos equivalem, respectivamente, ao $3^{\circ}$ e $4^{\circ}$ Movimentos, tendo o Ator A como o elaborador da reação.

É importante salientar que os Movimentos $7^{\circ}$ e $8^{\circ}$ finalizam a inclusão do público no jogo cênico (no $9^{\circ}$ Movimento, a triangulação retorna ao $1^{\circ}$ Movimento); ao final desses movimentos, a platéia se torna cúmplice, porém, do outro personagem (Ator A); ela está definitivamente "do lado" de todos os personagens; como afirma Soffredini, "O público é o vértice de maior peso no triângulo. É o cúmplice na representação. É o centro dela. É para ele que se conta a história, portanto ele é o dono dessa história. Muitas vezes ele conhece dados dela que os outros dois vértices do triângulo (os atores) desconhecem".
Fica evidente que o cerne da triangulação está nos Movimentos $3^{\circ}, 4^{\circ}, 7^{\circ}$ e $8^{\circ}$; quando o ator inclui a platéia no jogo cênico e define a reação do público.

Está claro que o sistema abordado possibilita uma série de alterações e modificações. Num mesmo espetáculo podem-se apresentar personagens que triangulam todo o tempo, apenas em alguns momentos, ou, ainda, que sequer se dispóem dessa maneira. Os procedimentos, portanto, em relação aos elementos da triangulação são flexíveis.

A pesquisa do Grupo de Teatro Mambembe (SP) alimentou diretamente seus três espetáculos iniciais e foi incorporada, de alguma forma, por todos os seus integrantes nos trabalhos posteriores, quer nos do próprio grupo, ou nos dos novos elencos aos quais se uniram, desenvolvendo, ampliando e divulgando as técnicas apreendidas. Foi um exemplo de iluminação da cena brasileira, que se apresenta nos edifícios teatrais, a partir daquela que se abriga na lona do universo circense.

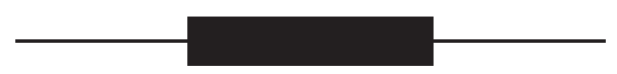

\section{Referências bibliográficas}

BRITO, R. J. S. Teatro de rua: princípios, elementos e procedimentos - a contribuição do Grupo de Teatro Mambembe (SP). Tese (Livre-docência). Campinas: UNICAMP, 2004.

FERNANDES, S. Grupos teatrais - anos 70. Campinas: Editora da UNICAMP, 2000.

LABAN, R. Dominio do Movimento. São Paulo: Summus, 1978.

SOFFREDINI, C. A. De um trabalhador sobre seu trabalho. Revista Teatro. São Paulo, n. 1, jun., 1980 , p. 4. 